\title{
Knowledge of Avulsion of Permanent Teeth Emergency Management Among Undergraduate in Brazilian Health Care Students
}

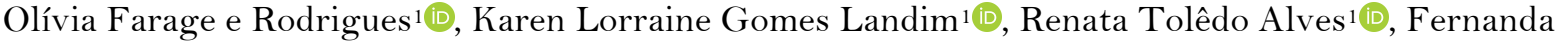 \\ Campos Machado ${ }^{(0)}$, Camila Faria Carrada1, 1 (D)
}

\footnotetext{
'Department of Paediatric Dentistry, School of Dentistry, Faculty of Medical Sciences and Health of Juiz de Fora, Juiz de Fora, MG, Brazil. ¿2Department of Social and Paediatric Dentistry, School of Dentistry, Federal University of Juiz de Fora, Juiz de Fora, MG, Brazil.

${ }^{3}$ Department of Paediatric Dentistry and Orthodontics, School of Dentistry, Federal University of Minas Gerais, Belo Horizonte, MG, Brazil.
}

Correspondence: Camila Faria Carrada, Faculdade de Odontologia, Universidade Federal de Minas Gerais, Avenida Antônio Carlos 6627, Pampulha, Belo Horizonte, MG, Brazil.31270-901. E-mail: camilacarrada_89@,hotmail.com

Academic Editor: Burak Buldur

Received: 06 May 2020 / Review: 22 June 2020 / Accepted: 05 August 2020

How to cite: Farage e Rodrigues O, Landim KLG, Alves RT, Machado FC, Carrada CF. Knowledge of avulsion of permanent teeth emergency management among undergraduate in Brazilian health care students. Pesqui Bras Odontopediatria Clín Integr. 2021; 21:e0085. https://doi.org/10.1590/pboci.2021.015

\begin{abstract}
Objective: To assess the knowledge of undergraduate health care students, about avulsion of permanent teeth. Material and Methods: It is a cross-sectional study. The sample consisted of Brazilian undergraduate students of the nursing, medicine, and dentistry degree programs. A structured questionnaire developed by the researchers, containing 18 objective questions about avulsion of permanent teeth was used as the data collection. Data analysis included Pearson's Chi-square and Fisher's Exact. Results: A total of $82.7 \%$ dental students, $22.9 \%$ nursing students, and $23 \%$ medical students had previously received some information about dental trauma. Students in the second half of the dentistry program had a higher percentage of correct answers in all questions $(\mathrm{p}<0.05)$. Being in the first or second half of the nursing program had no relation to the percentage of correct answers by students for any questions $(p>0.05)$. Students in the first half of the medical program had a higher percentage of correct answers for six of these questions $(\mathrm{p}<0.05)$. Dentistry students had the highest percentage of correct answers in all the questions $(\mathrm{p}<0.001)$. Conclusion: Although students from the dentistry degree program report having information on avulsion of permanent teeth, their practical experience was considered low. Upon comparing students from the dentistry, nursing, and medical degree programs regarding their learning about avulsion of permanent teeth, dentistry students had greater knowledge on the subject.
\end{abstract}

Keywords: Tooth Injuries; Tooth Avulsion; Students, Health Occupations; Child. 


\section{Introduction}

Dental trauma is considered the most frequent facial trauma of the human species [1]. Although falls are the most common cause, dentoalveolar injuries occur through various causes, such as traffic accidents [Q], sports accidents [3], work accidents [4], domestic accidents [5,6], among others. Currently, dental trauma is considered a public health problem due to its high prevalence, especially in children and adolescents, and because it can adversely affect the daily lives of the individuals involved [1]. Children suffering from traumatic dental injury may experience emotional stress, pain, and discomfort; thereby affecting their oral health related quality of life (OHRQoL) [7,8].

Dental trauma affects the orofacial region and appears in varied forms, with different complexities $[9,10]$. Avulsion of permanent teeth is dental trauma characterized by complete displacement of the tooth from its alveolus, and among all dentoalveolar trauma injuries, it is the one that causes the greatest damage to the support structures [10]. Tooth avulsion is responsible for approximately $16 \%$ of traumatic injuries [10]. Its prevalence in permanent teeth varies from $0.5 \%$ to $18.5 \% 10$. Its greatest incidence occurs in the upper central incisors and the age group most affected is 7 to 9 years of age [10,11].

According to guidelines published by the International Dental Traumatology Association (2012), the correct approach to a case of dental avulsion is extremely important [12]. Immediate replantation of the permanent tooth is the main treatment of choice. When this option is not feasible, the avulsed tooth must be stored in an appropriate medium to guarantee the integrity of the cells of the periodontal ligament and result in a good prognosis [12,13].

The prognosis for avulsed permanent teeth is not favorable, due to lack of information at the moment when first aid is given 14. Studies show that the successful management of the avulsed tooth begins at the accident site and in the first hours after its occurrence. This fact demonstrates the importance of health professionals knowing the measures to be taken in dental avulsion cases, since immediate and appropriate treatment, until the long-term follow-up [15].

Emergency medical services, which operate 24 hours a day, receive many patients with dental trauma, such as avulsion of permanent teeth. Often, the dentist is not the professional who administers first aid at the accident site [16]. Doctors, nurses and paramedical technicians can be the first to offer emergency primary treatment for these injuries [16]. The important role of health professionals in the treatment of dental traumatic injuries, such as avulsion of permanent teeth, requires education and training during their academic education [15-16].

To our knowledge, scarce investigations have evaluated the acquaintance of dental trauma management among Brazilian undergraduate students from general health programs. Thus, the present study aimed to assess the knowledge of undergraduate students of the nursing, medicine, and dentistry degree programs of a private University, about emergency procedures to be taken in avulsion of permanent teeth.

\section{Material and Methods}

Ethical Clearance

The study protocol was approved by the Human Research Ethics Committee (3.548.332). All volunteers signed the Free and Informed Consent Form (ICF) to authorize their participation in the research. 


\section{Study Design}

This is a cross-sectional observational study. Students from the dentistry, nursing, and medicine degree programs of a private University in Brazil participated in the study. Scholars from all semesters of the selected courses of study were included, regardless of age, sex, social class, and ethnicity. Participants who had any visual, neurological, intellectual, cognitive or motor impairments that prevented them from interpreting or answering the questionnaire's questions were excluded, as well as students who did not complete the questionnaire correctly were excluded.

Sample

The sample size was calculated to give a standard error of $5 \%$ and a $95 \%$ confidence interval level. The prevalence of students who knew or who performed the first emergency measure after dental avulsion was used: $13 \%$ for nursing students [13], 21\% for medical students [17] and 69\% for dental students [18]. The number of students enrolled in each degree program was: 146 students from the nursing degree program, 402 students from the dentistry degree program and 704 students from the medicine degree program. The calculation determined a minimal sample was: 55 nursing students, 232 medical students and 181 dental students.

\section{Data Collection}

Data collection was carried out from September to October 2019. The researchers went to the institution in the morning and afternoon shifts and approached the academics at the beginning or end of the class period. A structured self-applied questionnaire developed by the researchers based on similar studies, containing 18 objective questions about tooth avulsion was used as the data collection instrument [19,20]. The questionnaire was divided into three parts according to the coverage of the questions: from questions one to five (Q1-Q5) personal data were collected (age, sex, degree program, and program semester), from questions six to nine (Q6-Q9) previous experiences with permanent tooth avulsion were evaluated, and from questions ten to eighteen $\left(\mathrm{Q}_{10-Q 18}\right)$ knowledge about permanent tooth avulsion and the main emergency procedures to be taken when facing this type of trauma were evaluated. The correct answers to the questions were determined with reference to the 2012 avulsion guidelines of the International Association of Dental Traumatology [12].

\section{Data Analysis}

The data were organized into a database using the statistical software SPSS version 21.0 for Windows (SPSS Inc., Chicago, IL, USA). Descriptive analysis was done using absolute and relative frequency for categorical variables and mean and standard deviation values for numerical variables. The KolmogorovSmirnov test demonstrated non-normal distribution. To compare the frequency of correct answers between the first and second half of each degree program and between the dentistry, nursing, and medical studies programs, Pearson's Chi-square and Fisher's Exact tests were used. The level of significance was set at $5 \%(\mathrm{p}<0.05)$.

\section{Results}


A total of 606 students participated in the study, 231 from the dentistry program, 70 from the nursing program, and 305 from medicine. The mean age of the participants was 21.8 years. The data regarding the characteristics of the sample are presented in Table 1.

Table 1. Characterization of the sample.

\begin{tabular}{|c|c|c|c|c|c|c|}
\hline \multirow[b]{2}{*}{ Degree Program } & \multirow[b]{2}{*}{$\begin{array}{c}\text { Sample } \\
\mathrm{N}(\%)\end{array}$} & \multicolumn{2}{|c|}{ Semester Level } & \multicolumn{2}{|c|}{ Sex } & \multirow[b]{2}{*}{ Mean Age (SD) } \\
\hline & & $\begin{array}{l}\text { 1st Half } \\
\mathrm{N}(\%)\end{array}$ & $\begin{array}{l}\text { 2nd Half } \\
\text { N (\%) }\end{array}$ & $\begin{array}{l}\text { Female } \\
\mathrm{N}(\%)\end{array}$ & $\begin{array}{l}\text { Male } \\
\text { N (\%) }\end{array}$ & \\
\hline Dentistry & $231(38.1)$ & $106(17.5)$ & $125(20.6)$ & $179(29.5)$ & $52(8.6)$ & $21.4( \pm 3.2)$ \\
\hline Nursing & $70(50.3)$ & $40(6.6)$ & $30(5.0)$ & $68(11.2)$ & $2(0.3)$ & $22.5( \pm 5.9)$ \\
\hline Medicine & $305(11.6)$ & $193(31.8)$ & $112(18.5)$ & $212(35.0)$ & $93(15.3)$ & $22.1( \pm 3.3)$ \\
\hline Total & $606(100)$ & $339(55.9)$ & $267(44.1)$ & $459(75.7)$ & $147(24.3)$ & $21.8( \pm 3.7)$ \\
\hline
\end{tabular}

SD: Standard Deviation.

Table 2 presents the percentage data with respect to the previous experience of the dentistry, nursing, and medical students regarding tooth avulsion. The results showed that $82.7 \%$ of the dental students, $22.9 \%$ of the nursing students, and $23 \%$ of the medical students had previously received some type of information about dental trauma (Q5). For the dentistry students, the main source of information on the subject was in the classroom (52.8\%), while for the nursing students $(8.6 \%)$ and medical students $(7.2 \%)$, through some book or journal (Q6). More than half of the students from all the disciplines never had experience with dental trauma (Q7). And those who had previous experience had contact mainly due to dental trauma that happened to some family member (Q8). Most of the dentistry students (62.8\%) felt they had a little knowledge about dental trauma. While for the students in nursing and in medicine, $55.4 \%$ and $61.5 \%$, respectively, reported not having knowledge about the subject (Q9).

Table 2. Previous experience of dentistry, nursing, and medical students in relation to tooth avulsion.

\begin{tabular}{|c|c|c|c|}
\hline Questions & $\begin{array}{c}\text { Dentistry } \\
\mathrm{N}(\%)\end{array}$ & $\begin{array}{c}\text { Nursing } \\
\mathrm{N}(\%)\end{array}$ & $\begin{array}{c}\text { Medicine } \\
\text { N (\%) }\end{array}$ \\
\hline \multicolumn{4}{|c|}{ Q5 - Have you previously received any information about dental trauma? } \\
\hline Yes & $191(82.7)$ & $16(22.9)$ & $70(23.0)$ \\
\hline No & $40(17.3)$ & $53(75.7)$ & $235(77.0)$ \\
\hline \multicolumn{4}{|l|}{ Q6 - If yes, where? } \\
\hline At Home & $14(6.1)$ & $3(4.3)$ & $26(8.6)$ \\
\hline In Classes at the University & $122(52.8)$ & $3(4.3)$ & $4(1.3)$ \\
\hline In a Training Program & $1(0.4)$ & $0(0.0)$ & $1(0.3)$ \\
\hline In Some Book or Journal & $17(7.4)$ & $6(8.6)$ & $22(7.2)$ \\
\hline With my Dentist or Other Healthcare Professional & $3(1.3)$ & $1(1.4)$ & $3(1.0)$ \\
\hline Radio, TV, or Internet & $0(0.0)$ & $0(0.0)$ & $1(0.3)$ \\
\hline Other & $0(0.0)$ & $0(0.0)$ & $0(0.0)$ \\
\hline \multicolumn{4}{|c|}{ Q7 - Have you or did you have any experience with dental trauma? } \\
\hline Yes & $73(31.6)$ & $10(14.3)$ & $64(21.0)$ \\
\hline No & $158(68.4)$ & $59(84.3)$ & $241(79.0)$ \\
\hline \multicolumn{4}{|l|}{ Q8 - If yes, how? } \\
\hline Occurred with a Family Member & $26(11.3)$ & $8(11.4)$ & $22(39.3)$ \\
\hline In an Internship and/or Patient Care in College & $23(10.0)$ & $0(0.0)$ & $0(0.0)$ \\
\hline Engaging in Sports and/or Recreation & $0(0.0)$ & $0(0.0)$ & $29(9.5)$ \\
\hline Other & $0(0.0)$ & $2(2.9)$ & $3(1.0)$ \\
\hline \multicolumn{4}{|c|}{ Q9 - How do you consider your knowledge about dental trauma? } \\
\hline I Don't Know & $21(12.0)$ & $44(55.4)$ & $181(61.5)$ \\
\hline I Know Little & $145(62.8)$ & $25(35.7)$ & $122(40.0)$ \\
\hline I Know Enough & $58(25.1)$ & $0(0.0)$ & $1(0.3)$ \\
\hline
\end{tabular}


Table 3 shows the comparison between the first and second half of each degree program in relation to knowledge about dental avulsion. For the dentistry program, being in the first or second half of the degree program is related to the percentage of correct answers by the students in all nine questions about tooth avulsion. Students in the second half of the dentistry program had a higher percentage of correct answers in all questions evaluated ( $<<0.05)$. Being in the first or second half of the nursing program had no relation to the percentage of correct answers by students for any of the nine questions about dental avulsion ( $\mathrm{p}>0.05$ ) (Table 3 ).

\section{Table 3. Comparison between the first and second half of each degree program in relation to knowledge about tooth avulsion.}

\begin{tabular}{|c|c|c|c|c|c|c|c|c|c|}
\hline \multirow[b]{2}{*}{ Questions and Correct Answers } & \multicolumn{3}{|c|}{ Dentistry } & \multicolumn{3}{|c|}{ Nursing } & \multicolumn{3}{|c|}{ Medicine } \\
\hline & $\begin{array}{l}1^{\text {st }} \text { Half } \\
\mathrm{N}(\%)\end{array}$ & $\begin{array}{l}2^{\text {nd }} \text { Half } \\
\mathrm{N}(\%)\end{array}$ & p-value & $\begin{array}{l}1^{\text {st }} \text { Half } \\
\mathrm{N}(\%)\end{array}$ & $\begin{array}{l}2^{\text {nd }} \text { Half } \\
\mathrm{N}(\%)\end{array}$ & p-value & $\begin{array}{l}1^{\text {st }} \text { Half } \\
\mathrm{N}(\%)\end{array}$ & $\begin{array}{l}2^{\text {nd }} \text { Half } \\
\mathrm{N}(\%)\end{array}$ & p-value \\
\hline $\begin{array}{l}\text { Q10 - How would you define tooth avulsion? } \\
\text { Complete displacement of the tooth from its alveolus }\end{array}$ & $64(60.4)$ & $115(92.0)$ & $0.01 *$ & $20(50.0)$ & $18(60.0)$ & 0.40 & $141(73.1)$ & $54(48.2)$ & $0.01 *$ \\
\hline $\begin{array}{l}\text { Q11 - What is the immediate emergency action you would take in a case of tooth } \\
\text { avulsion? } \\
\text { Find the tooth, wash it, and put it back in its place / Store the tooth in a } \\
\text { suitable liquid and seek a professional who will help }\end{array}$ & $38(35.8)$ & $102(81.6)$ & $0.01 *$ & $7(17.5)$ & $9(30.0)$ & 0.21 & $108(56.0)$ & $36(32.1)$ & $0.01 *$ \\
\hline $\begin{array}{l}\text { Q12 - Do you think it is important to store the avulsed tooth? } \\
\text { Yes }\end{array}$ & $92(86.8)$ & $212(96.8)$ & $0.01 *$ & $33(82.5)$ & $24(80.0)$ & 0.79 & $175(90.7)$ & $85(75.9)$ & $0.01 *$ \\
\hline $\begin{array}{l}\text { Q13 - If yes, what would you use to store the avulsed tooth: } \\
\text { A container with milk / A container with saline / I would put it in the child's } \\
\text { mouth }\end{array}$ & $52(49.1)$ & $104(83.2)$ & $0.01 *$ & $12(30.0)$ & $14(46.7)$ & 0.15 & $125(64.8)$ & $47(42.0)$ & $0.01 *$ \\
\hline $\begin{array}{l}\text { Q14 - Did you know that it is possible to replant an avulsed tooth? } \\
\text { Yes }\end{array}$ & $64(60.4)$ & $113(90.4)$ & $0.01 *$ & $19(47.5)$ & $17(56.7)$ & 0.44 & $140(72.5)$ & $55(49.1)$ & $0.01 *$ \\
\hline $\begin{array}{l}\text { Q15 - Give the correct definition for replantation: } \\
\text { Placement of the same teeth that were avulsed in the dental alveolus }\end{array}$ & $69(65.1)$ & $115(92.0)$ & $0.01 *$ & $22(55.0)$ & $20(66.7)$ & 0.32 & $147(76.2)$ & $65(58.0)$ & $0.01 *$ \\
\hline $\begin{array}{l}\text { Q16 - Who is the right person to perform the replantation? } \\
\text { Anyone who helped the patient at the time of the tooth avulsion and if they } \\
\text { think they are able to do this }\end{array}$ & $\mathrm{O}(0.0)$ & $8(6.4)$ & $0.01^{\circ}$ & $\mathrm{O}(0.0)$ & $\mathrm{o}(0.0)$ & & $1(0.5)$ & $8(7.1)$ & $0.01 *$ \\
\hline $\begin{array}{l}\text { Q17 - How long do you think the tooth can stay out of the alveolus without } \\
\text { damaging treatment? } \\
\text { The least time possible }\end{array}$ & $50(47.2)$ & $83(66.4)$ & $0.01 *$ & $21(52.5)$ & $11(36.7)$ & 0.18 & $105(54.4)$ & $53(47.3)$ & 0.22 \\
\hline $\begin{array}{l}\text { Q18 - Do you think it is necessary to have the patient monitored by a dentist after } \\
\text { replantation? } \\
\text { It is necessary }\end{array}$ & $90(84.9)$ & $123(98.4)$ & $0.01 *$ & $33(82.5)$ & $26(86.7)$ & 0.63 & $175(90.7)$ & $97(86.6)$ & 0.27 \\
\hline
\end{tabular}

*Pearson's chi-square test; ${ }^{\circ}$ Fisher's exact test. 
For the medical degree program, being in the first or second half of the program is related to the percentage of correct answers by the students for seven of the nine questions about dental avulsion. Students in the first half of the medical program had a higher percentage of correct answers for six of these questions: definition of dental avulsion $(\mathrm{p}=0.01)$, what is your action regarding a dental avulsion $(\mathrm{p}=0.01)$, importance of storing the avulsed tooth $(\mathrm{p}=0.01)$, storage location $(\mathrm{p}=0.01)$, knowledge about avulsed tooth replantation $(p=0.01)$, definition of replantation $(p=0.01)$. Students in the second half of the medical program had a higher percentage of correct answers for one of the questions: who is the right person to perform replantation of the avulsed tooth $(\mathrm{p}=0.01)$ (Table 3$)$.

Table 4 compares the knowledge about tooth avulsion among the students in the dentistry, nursing, and medical degree programs. There is a relationship between the type of degree and the percentage of correct answers in seven of the nine questions about tooth avulsion. Dentistry students had the highest percentage of correct answers in all the questions evaluated $(\mathrm{p}<0.001)$.

Table 4. Comparison between degree programs in relation to knowledge about tooth avulsion.

\begin{tabular}{ccccc}
\hline Questions & Dentistry & Nursing & Medicine & p-value \\
& $\mathrm{N}(\%)$ & $\mathrm{N}(\%)$ & $183(60.0)$ & $<0.001^{*}$ \\
\hline Q10 & $179(77.5)$ & $15(21.4)$ & $62(20.3)$ & $<0.001^{*}$ \\
Q11 & $140(60.6)$ & $4(5.7)$ & $255(83.6)$ & $<0.001^{*}$ \\
Q12 & $213(92.2)$ & $44(62.9)$ & $94(30.8)$ & $<0.001^{*}$ \\
Q13 & $156(67.5)$ & $15(21.4)$ & $162(53.1)$ & $<0.001^{*}$ \\
Q14 & $177(76.6)$ & $16(22.9)$ & $191(62.6)$ & $<0.001^{*}$ \\
Q15 & $184(79.7)$ & $27(38.6)$ & $2(0.7)$ & 0.053 \\
Q16 & $8(3.5)$ & $1(1.4)$ & $144(47.2)$ & $<0.001^{*}$ \\
Q17 & $133(57.6)$ & $23(32.9)$ & $253(83.0)$ & $0.003^{*}$ \\
Q18 & $213(92.2)$ & $56(80.0)$ & & \\
\hline
\end{tabular}

*Pearson's chi-square test.

\section{Discussion}

The present study revealed data about the knowledge of students in dentistry, nursing, and medical degree programs regarding the avulsion of permanent teeth. In recent decades, studies have reported a lack of knowledge about dental avulsion by professionals already working in the health field $[9,19-26]$. However, there is still a shortage in the literature in relation to the level of knowledge and the main emergency procedures for handling a case of tooth avulsion, among students of courses in the health field. Investigating the knowledge about tooth avulsion, among dentistry, nursing, and medical professionals still in training, can help in identifying the learning gap about this type of trauma.

The results show that most of the dentistry program students had previously received information about tooth avulsion, with the classroom being the main source of this theoretical knowledge. This does not mean that dentistry students are able to treat the traumatized patient, since only $10 \%$ of students reported having some practical experience with the subject during their undergraduate training and $25 \%$ said they had sufficient knowledge on the subject. These results are similar to those of other studies, which point to the fact that students in the dentistry program present knowledge of the theoretical content on the subject, but they have little practical experience to handle a case of tooth avulsion in a real emergency situation [17,26-29]. According to a previous study, the average knowledge about dental avulsion management depends on the dentist's clinical experience [7]. This includes the importance of a practical approach to the subject in undergraduate courses. The dentistry undergraduate curriculum has lectures on dental trauma [7-21,28]. 
However, undergraduate students have no practical knowledge in the management of dental avulsion [7$21,28]$

For the nursing and medicine programs, less than a third of the students reported having access to information on tooth avulsion. Of these, less than $5 \%$ indicated undergraduate classes as the main source of knowledge about the trauma. Among the nursing students, $14 \%$ reported already having practical experience with the topic and for the medical students, $21 \%$. No student from either of the two programs indicated that their practical experience with tooth avulsion was gained with patients during their undergraduate activities. In an earlier study, $72 \%$ of the students in a nursing course in Poland reported that their knowledge about dental trauma came from self-education [13]. Similarly, in a study with medical students in Croatia, only $21 \%$ of the students reported having information about tooth avulsion during their undergraduate studies [18].

In a study carried out with 121 dental students, there was a deficiency in the students' knowledge about tooth avulsion, especially in those who were in their initial semesters of undergraduate studies [29]. The findings of the present study are consistent with the data in the literature, given that when comparing the knowledge about tooth avulsion among students in the first and second half of each program, it was observed that for the dentistry and nursing programs, being in the first or second half is related to the percentage of correct answers from the students. In both programs, students in the second half had a higher percentage of correct answers than students in the first half of the program. While for medicine, this data was reversed, students in the second half of the program had a lower percentage of correct answers than those in the first half, suggesting that this knowledge is forgotten during the course of undergraduate studies.

When comparing knowledge about tooth avulsion among dentistry, nursing, and medical students, dentistry students had the highest percentage of correct answers in all the questions evaluated. Previous research suggests that, with the exception of the dentistry program, degree programs in the health field do not include approaches to dental trauma in their course curricula [13,30] and/or that the students in these courses do not assign importance to the information provided by the lecture classes on this subject [13].

The prognosis for the treatment of an avulsion of permanent teeth is related, among other factors, to the actions taken during the first minutes after the trauma [31]. The study by Unal et al. [32] showed that in $65 \%$ of the cases of tooth avulsion, the time from trauma until arrival at the dentist's office exceeds $60 \mathrm{~min}$ $[13,32]$. Therefore, the medical team responsible for first aid must be prepared to do immediate replanting or to preserve the tooth in cases of delayed replanting, a fact that was not observed in this study [13]. Of the dentistry students evaluated, $60.6 \%$ would do immediate replantation of the avulsed tooth at the accident site and $67.5 \%$ knew where to store the avulsed tooth if there was no immediate replantation. However, only $5.7 \%$ and $20.3 \%$ of the nursing and medical students, respectively, would do replantation in a case of dental avulsion, and $21.4 \%$ of nursing students and $30.8 \%$ of medical students would know the correct location for tooth storage until replantation could occur.

Limitations of the present study can be pointed out, such as those inherent in cross-sectional studies. In addition, there is no standardized validated questionnaire for assessing knowledge about dental avulsion. Such methodological heterogeneity between studies can make comparisons between populations difficult. The importance of investigating, in other studies, two topics on the conduct of permanent tooth avulsion that were not included in the present study is highlighted: where to hold an avulsed tooth and what solution should be used to wash an avulsed tooth if it is dirty. Among the strengths of the research, we highlight the fact that the sample size accommodates the statistical analyzes performed. It is also noteworthy that the correction of the questionnaire responses was based on evidence-based guidelines on dental traumatology [12]. 
Health care professionals must have basic knowledge about dental avulsion, since they may be asked to intervene in cases of dental trauma, or even assist in guiding lay people. The evidence of the presence of a gap in the training of health professionals reflects in their inability to deal with emergency situations of dental trauma [32,33]. Limited teaching on avulsion of permanent teeth during undergraduate health courses hardly offers enough experience for the development of clinical skills for the management of this dental trauma. Thus, it is necessary to get more familiar with the international recognized evidence-based guidelines on dental traumatology, which are revised on a regular basis and to invest in continuing education to improve on the undergraduate training of health professionals regarding this topic.

\section{Conclusion}

The present study showed that, although students from the dentistry degree program report having information on dental avulsion in their undergraduate training, their practical experience was considered low. Students from the nursing and medical degree program reported not having theoretical and practical experience about dental trauma. Upon comparing students from the dentistry, nursing, and medical degree programs regarding their learning about dental avulsion, dentistry students had greater knowledge on the subject.

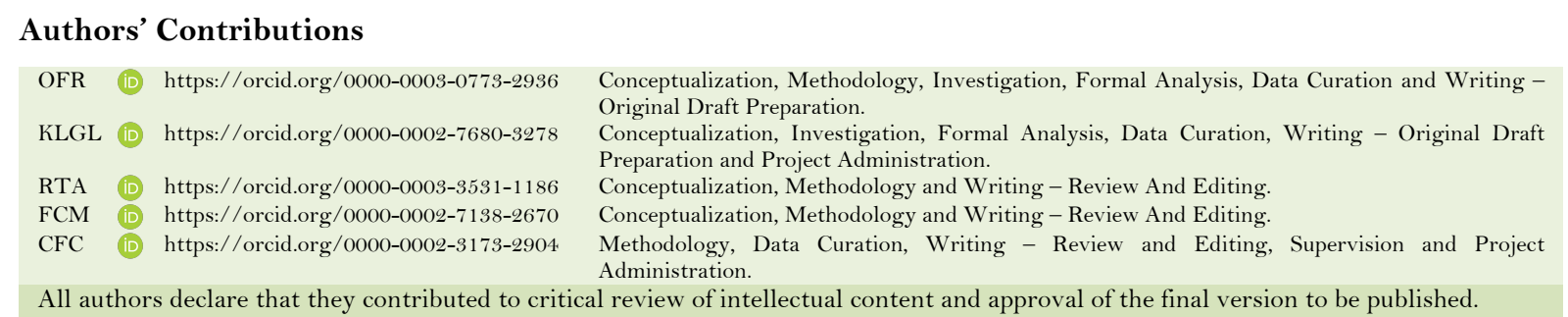

\section{Financial Support}

The School of Dentistry; School of Medical Sciences - SUPREMA; the Brazilian Coordination of Higher Education, Ministry of Education (CAPES); the Research Foundation of the State of Minas Gerais (FAPEMIG) and the National Council for Scientific and Technological Development (CNPQ).

\section{Conflict of Interest}

The authors declare no conflicts of interest.

\section{Data Availability}

The data used to support the findings of this study can be made available upon request to the corresponding author

\section{References}

[1] O'Neil DW, Clark MV, Lowe JW, Harrington MS. Oral trauma in children: a hospital survey. Oral Surg Oral Med Oral Pathol 1989; 68(6):691-6. https://doi.org/10.1016/0030-4220(89)90157-6

[Q] Silva AC, Passeri LA, Mazzonetto R, Moraes M, Moreira RWF. Incidence of dental trauma associated with facial trauma in Brazil: a 1-year evaluation. Dental Traumatol 2004; 20(1):6-11. https://doi.org/10.1111/j.1600-4469.2004.00212.x

[3] Zhang X, Gong Y. Characteristics of avulsed permanent teeth treated at Beijing Stomatological Hospital. Dental Traumatol 2011; 27(5):379-84. https://doi.org/10.1111/j.1600-9657.2011.01024.x

[4] Tuli T, Hächl O, Rasse M, Kloss F, Gassner R. Dentoalveolar trauma. Analysis of 4763 patients with 6237 injuries in 10 years. Mund Kiefer Gesichtschir 2005; 9(5):324-9.

[5] Enabulele JE, Oginni AO, Sede MA, Oginni FO. Pattern of traumatised anterior teeth among adult Nigerians and complications from late presentation. BMC Res Notes 2016; 9:70. https://doi.org/10.1186/s13104-016-1871-3 
[6] Garbin CAS, Guimarães e Queiroz APD, Rovida TAS, Garbin AJI. Occurrence of traumatic dental injury in cases of domestic violence. Braz Dent J 2012; 23(1):72-6. https://doi.org/10.1590/s0103-64402012000100013

[7] Buldur B, Güvendi ON. Conceptual modelling of the factors affecting oral health-related quality of life in children: A path analysis. Int J Paediatr Dent 2020; 30(2):181-92. https://doi.org/10.1111/ipd.12583

[8] Bendo CB, Paiva SM, Varni, JW, Vale MP. Oral health-related quality of life and traumatic dental injuries in Brazilian adolescents. Community Dent Oral Epidemiol 2014; 42(3):2 16-23. https://doi.org/10.1111/cdoe.12078

[9] Yver SS, Panigrahi A, Sharma S. Knowledge and awareness of first aid of avulsed tooth among physicians and nurses of Hospital Emergency Department. J Pharm Bioallied Sci 2017; 9(2):94-8. https://doi.org/10.4103/jpbs.jpbs_343_16

[10] Andreasen JO, Andreasen FM, Skeie A, Hjørting-Hansen E, Schawartz O. Effect of treatment delay upon pulp and periodontal healing of traumatic dental injuries - a review article. Dental Traumatol 2002; 18(3):116-28. https://doi.org/10.1034/j.1600-9657.2002.00079.x

[11] Andreasen JO, Andreasen FM. Textbook and Colorful Atlas of Traumatic Teeth Injuries. Copenhague: Blackwell Munksgaard; 2008.

[12] Andersson L, Andreasen JO, Day P, Heithersay G, Trope M, Diangelis AJ. International Association of Dental Traumatology guidelines for the management of traumatic dental injuries: 2. Avulsion of permanent teeth. Dental Traumatol 2012; 28(2):88-96. https://doi.org/10.1111/j.1600-9657.2012.01125.x

[13] Baginska J, Rodakowska E, Milewski R, Wilczynska-Borawska M, Kierklo A. Polish school nurses' knowledge of the first-aid in tooth avulsion of permanent teeth. BMC Oral Health 2016; 16:30. https://doi.org/10.1186/s12903-016-0183-2

[14] Glendor U, Halling A, Andersson L, Eilert-Petersson E. Incidence of traumatic tooth injuries in children and adolescents in the county of Västmanland, Sweden. Swed Dent J 1996; 20(1-2):15-28.

[15] Mesquita GC, Soares PBF, Moura CCG, Roscoe MG, Paiva SM, Soares CJ. A 12-Year Retrospective Study of Avulsion Cases in a Public Brazilian Dental Trauma Service. Brazi Dent J 2017; 28(6):749-56. https://doi.org/10.1590/0103-6440201701610

[16] Díaz J, Bustos L, Herrera S, Sepulveda J. Knowledge of the management of paediatric dental traumas by non-dental professionals in emergency rooms in South Araucanía, Temuco, Chile. Dent Traumatol 2009; 25(6):611-9. https://doi.org/10.1111/j.1600-9657.2009.00835.x

[17] Jokic NI, Bakarcic D, Grzic R, Maistorovic M, Sostarek M. What general medicine students of University of Rijeka know about dental avulsion?. Eur J Dent Educ 2017; 21(4):e131-e134. https://doi.org/10.1111/eje.12235

[18] Santos M, Neto M, Souza C, Soares D, Plameira P. Level of knowledge of Nursing, Physical Education and Dentistry students about avulsion dentoalveolar trauma: preliminary study. Rev Cir Traumatol Buco-maxilo-facial 2010; 10(1):95-102.

[19] Duruk G, Erel ZB. Assessment of Turkish dentists' knowledge about managing avulsed teeth. Dent Traumatol 2020; 36(4):371-81. https://doi.org/10.1111/edt.12543

[20] Hartmann, RC, Rossetti BR, Pinheiro LS, Figueiredo JAP, Rossi-Fedele G, Gomes MS, et al. Dentists' knowledge of dental trauma based on the International Association of Dental Traumatology Guidelines: a survey in South Brazil. Dent Traumatol 2019; 35(1):27-32. https://doi.org/10.1111/edt.12450

[21] Vasconcellos LGO, Brentel AS, Vanderlei AD, Vasconcellos LMR, Valera MC, Araújo MAM. Knowledge of general dentists in the current guidelines for emergency treatment of avulsed teeth and dental trauma prevention. Dent Traumatol 2009; 25(6):578-83. https://doi.org/10.1111/j.1600-9657.2009.00820.x

[22] Glendor U. Has the education of professional caregivers and lay people in dental trauma care failed? Dent Traumatol 2009; 25(1):12-8. https://doi.org/10.1111/j.1600-9657.2008.00707.x

[23] Kumar S, Sajjanar AB, Athulkar M, Sajjanar J, Shewale A, Wasnik M, et al. The status of knowledge related to the emergency of avulsed tooth amongst the medical practitioners of Nagpur, Central India. J Clin Diagn Res 2017; 11(5):ZC2 1-ZC24. https://doi.org/10.7860/jcdr/2017/26422.9811

[24] Ulusoy AT, Onder H, Cetin B, Kaya S. Knowledge of medical hospital emergency physicians about the first-aid management of traumatic tooth avulsion. Int J Paediatr Dent 2012; 22(3):211-6. https://doi.org/10.1111/j.1365-263x.2011.01178.x

[25] Buldur B, Kapdan A. Factors associated with knowledge and attitude of management of traumatic dental injuries: A cross-sectional study among Turkish dentists. Pesqui Bras Odontopediatria Clín Integr 2018; 18(1):e3948. https://doi.org/10.4034/PBOCI.2018.181.30

[26] Qasi SR, Nasir KS. First-aid knowledge about tooth avulsion among dentists, doctors and lay people. Dental Traumatol 2009; 25(3):295-9. https://doi.org/10.1111/j.1600-9657.2009.00782.x

[27] Traebert J, Traiano ML, Armênio R, Barbieri DB, Lacerda JT, Marcenes W. Knowledge of lay people and dentists in emergency management of dental trauma. Dental traumatol 2009; 25(3):277-83. https://doi.org/10.1111/j.1600-9657.2009.00779.x

[28] Limbu S, Dikshit P, Bhagat T, Mehata S. Knowledge of dental interns towards emergency management of avulsed tooth in dental colleges in Nepal. J Nepal Health Res Counc 2014; 12(26):1-7. 
[29] Fujita Y, Shiono Y, Maki K. Knowledge of emergency manageent of avulsed tooth among Japanese dental students. BMC Oral Health 2014; 14:34. https://doi.org/10.1186/1472-6831-14-34

[30] Souza RLF, Santos CAO, Caldas ATL, Salviano CMR, Serpa EBM, Campos FAT. Avulsion of permanent teeth: the knowledge of odontology undergrads. REFACS 2018; 6(2):199-205. https://doi.org/10.18554/refacs.v6i2.2815

[31] Fouad AF, Abbott PV, Tsilingaridis G, Cohenca N, Lauridsen E, Bourguignon C, et al. International Association of Dental Traumatology guidelines for the management of traumatic dental injuries: 2. Avulsion of permanent teeth. Dent Traumatol 2020; 36(4):331-42. https://doi.org/10.1111/edt.12573

[32] Unal M, Oznurhan F, Kapdan A, Aksoy S, Dürer A. Traumatic dental injuries in children. Experience of a hospital in the central Anatolia region of Turkey. Eur J Paediatr Dent 2014; 15(1):17-22.

[33] Nagata JY, Góis VLA, Münchow EA, Albuquerque MTP. Dental trauma education intervention as a positive influence among undergraduate students. Eur J Dent 2018; 12(4):502-7. https://doi.org/10.4103/ejd.ejd_148_18 